\title{
EL SISTEMA DE FUENTES DEL DERECHO DE EXCEPCIÓN DURANTE LA PANDEMIA: UNA BRECHA DE SEGURIDAD EN EL ORDENAMIENTO JURÍDICO
}

\section{THE SYSTEM OF SOURCES OF THE RIGHT OF EXCEPTION DURING THE PANDEMIC: A SECURITY GAP IN THE LEGAL SYSTEM}

\author{
Manuel Jesús López Baroni \\ Universidad Pablo de Olavide. Sevilla, España \\ mjlopbar1@upo.es
}

Recibido: octubre de 2020

Aceptado: noviembre de 2020

\begin{abstract}
Palabras clave: Sistema de fuentes del derecho de excepción; sistema de fuentes ordinario; estado de alarma; estado de excepción; medidas extraordinarias: derechos fundamentales.

Keywords: System of sources of the right of exception; ordinary source of law; state of alarm; state of exceptions; extraordinary measures: fundamental rights.
\end{abstract}

Resumen: Nunca en la historia de nuestra democracia habíamos asistido a una limitación y/o suspensión de derechos tan grave y duradera en el tiempo como la vivida durante la pandemia. Por ello, resulta necesario analizar el sistema de fuentes del derecho de excepción contrastando sus características con las del sistema de fuentes ordinario. Para cumplir este objetivo, tendremos que comparar a su vez las características del estado de alarma con el de excepción, y ambos, con las medidas extraordinarias que permite la legislación ordinaria. Con este fin emplearemos siete criterios, lo que nos permitirá, además de clarificar ambos sistemas de fuentes, poner de manifiesto cómo el estado de alarma ha provocado una brecha en la seguridad de nuestro ordenamiento jurídico que debe ser resuelta cuanto antes.

Abstract: Never in the history of democracy have we witnessed such a serious and long-lasting limitation and / or suspension of rights as that experienced during the pandemic. Therefore, it is necessary to analyze the system of sources of the right of exception by contrasting its characteristics with those of the ordinary source system. To achieve this objective, we will have to compare the characteristics of the state of alarm with that of exception, and both, with the extraordinary measures allowed by ordinary legislation. To this end, we will use seven criteria, which will allow us, in addition to clarifying both source systems, to show how the state of alarm has caused a gap in the security of our legal system that must be solved as soon as possible. 


\section{Introducción}

La pandemia ha supuesto una prueba de estrés para las democracias liberales occidentales. El hecho de que el primer confinamiento masivo se produjese en la dictadura china condicionó de alguna manera las medidas a adoptar en Europa, primero en Italia y poco después en España, forzando nuestros respectivos ordenamientos jurídicos para una situación que difícilmente pudo preverse cuando se legisló sobre este tipo de eventos extraordinarios.

Pues bien, en el presente artículo analizaremos el sistema de fuentes del derecho de excepción, comparándolo con el sistema de fuentes ordinario. Pero, para ello, hemos de contrastar las características del estado de alarma con las del estado de excepción, y a su vez, el de ambos con las medidas extraordinarias que se pueden adoptar con la legislación ordinaria. Esto nos permitiría someter a crítica las medidas adoptadas durante los meses de marzo y junio, dado que han supuesto la mayor restricción de derechos fundamentales desde el restablecimiento de la democracia en nuestro país; y, en última instancia, poner de manifiesto una brecha de seguridad que se ha abierto en nuestro ordenamiento jurídico, con objeto de que se resuelva cuanto antes porque puede afectar a la estabilidad del propio sistema democrático.

El presupuesto de partida a principios de este año, al menos, en el plano teórico, es que el estado de alarma es menos lesivo para los ciudadanos, y por ende, más democrático (restringe menos), que el de excepción. Sin embargo, este axioma es erróneo. Como mostraremos, la distinción entre los estados de alarma y excepción no reside (necesariamente) en la restricción cuantitativa o cualitativa de los derechos fundamentales, sino en el grado de control inicial parlamentario; y en este sentido, el estado de excepción es, sin duda, más garante para los ciudadanos, lo que unido a que no necesariamente es más limitativo, conlleva una necesaria e incómoda reflexión a posteriori.

Además, las medidas previstas para eventos extraordinarios en el sistema de fuentes ordinario pueden ser más restrictivas, no ya que el estado de alarma, sino incluso que el propio estado de excepción, pero sin que se sustraigan estas restricciones del control por parte de la jurisdicción ordinaria, lo que también conlleva turbadores interrogantes acerca de la naturaleza del sistema de fuentes del derecho de excepción.

Por último, la ausencia de un criterio de demarcación nítido entre el estado de alarma y el de excepción conllevó que el decreto se alarma se mostrara insuficiente para unas cuestiones, porque no se quiso adoptar el estado de excepción, pero fuese excesivo en otras, invadiendo medidas propias de dicho estado. ${ }^{1}$ Para corregir esta anomalía, se empleó el sistema de fuentes ordinario, de forma que para combatir la pandemia hemos simultaneado los dos sistemas de fuentes. La paradoja es que las mayores restricciones que hemos sufrido no han sido consecuencia directa del decreto del estado de alarma, sino de las normas ordinarias dictadas durante su vigencia, lo que ha generado mucha confusión e inseguridad jurídica.

1. El estado de alarma se decretó mediante el Real Decreto 463/2020, de 14 de marzo, por el que se declara el estado de alarma para la gestión de la situación de crisis ocasionada por el COVID-19. 


\section{Los criterios de demarcación entre el sistema de fuentes del derecho de excepción y el sistema de fuentes ordinario}

El sistema de fuentes del derecho de excepción se puede comparar con el sistema de fuentes ordinarias del derecho atendiendo a tres variables: a) el rango de las normas que se dicta durante un periodo de alarma; b) los derechos que pueden limitarse o suspenderse con ambos sistemas de fuentes; b) la jurisdicción competente para examinar tanto las normas como las restricciones de derechos.

Pero para poder establecer esta comparación hay que examinar a su vez los criterios de distinción entre los estados de alarma y excepción, de un lado, y entre estos estados y las medidas que se pueden adoptar con la legislación ordinaria para situaciones de excepcionalidad, de otro.

Pues bien, vamos a examinar el entrecruzamiento de estos dos sistemas de fuentes (derecho de excepción y derecho ordinario) y tres estados de excepcionalidad (alarma, excepción y medidas extraordinarias del derecho ordinario), con arreglo a siete criterios, $^{2}$ teniendo en cuenta lo

2. Por supuesto, hay más criterios posibles, por ejemplo, el de "competencia", que permite la recentralización. Pero tampoco es un criterio unánime. Así, Pérez Royo (2020) sostiene textualmente que "El estado de alarma no es un instrumento de "centralización política", mientras que Nogueira cita a otros destacados juristas (Arbós o Tajadura) que se inclinarían por destacar la alteración en la distribución de las competencias y los mecanismos de "estatalización" como características distintivas de este tipo de estados. (Nogueira, 2020). sucedido entre el 15 de marzo y el 21 de junio por la pandemia. ${ }^{3}$

\section{2.l Por las causas y/o los efectos}

El artículo 4.b de la Ley 4/1981 establece que el estado de alarma se declarará, ${ }^{4}$ entre otros motivos, por "Crisis sanitarias, tales como epidemias y situaciones de contaminación graves". El artículo 12.1 ahonda en esta temática, al remitirse, en cuanto a las medidas que se pueden adoptar, a "las establecidas en las normas para la lucha contra las enfermedades infecciosas".

El estado de excepción, por el contrario, no es causal, es decir, no se define por motivos concretos, que ni siquiera están enumerados a título ejemplificativo, sino por las consecuencias o efectos de una situación de anormalidad. Así, el artículo 13.1 de la Ley 4/81 establece que:

Cuando el libre ejercicio de los derechos y libertades de los ciudadanos, el normal funcionamiento de las instituciones democráticas, el de los servicios esenciales para la comunidad o cualquier otro aspecto del orden público, resulten tan gravemente alterados que el ejercicio de las potestades ordinarias resulte insuficiente para restablecerlo y mantenerlo (...)

Si analizamos conjuntamente los dos artículos, podemos constatar cómo: a) la situación de pandemia no está prevista para el estado de alarma (se recogen las epidemias, pero aquella afecta a un ámbito territorial mucho más amplio y, por ende, de mayor gravedad); b) lo relevante

3. En ese período estuvimos bajo el estado de alarma en España.

4. Ley Orgánica 4/1981, de 1 de junio, de los estados de alarma, excepción y sitio. 
del estado de excepción no es la causa, sino los efectos que provoca en el orden público; c) para que se declare el estado de excepción, resulta innecesario que no basten con las medidas adoptadas en el estado de alarma (aquel estado no es una versión cualificada de este), sino que "el ejercicio de las potestades ordinarias resulte insuficiente para restablecer y mantener el orden público" (nota: las cursivas son mías): d) para que se declare el estado de excepción, no hace falta una alteración del orden público, sino que basta con que "el libre ejercicio de los derechos y libertades de los ciudadanos" o "el funcionamiento de las instituciones democráticas" resulten "gravemente alterados"; e) una situación de pandemia, e incluso de epidemia, podría justificar la aplicación del estado de excepción si los efectos de la misma alteran el "orden público", el "libre ejercicio de los derechos y ciudadanos", o el "funcionamiento de las instituciones democráticas"; f) aunque pueda parecer absurdo, tal y como está redactada la ley, no son excluyentes, de forma que, en puridad podrían decretarse los dos estados a la vez. En efecto, como el estado de excepción no es una versión agravada del de alarma, y aquel parece definirse por los efectos y esta, la alarma, por las causas, desde un punto de vista estrictamente teórico no es imposible decretar los dos estados a la vez, lo que demuestra las carencias de la ley a la hora de delimitar nítidamente ambos estados. Podríamos sostener que contraría el sentido común, pero no la lógica (quizá esta anomalía explique que durante el estado de alarma se aplicaran simultáneamente las medidas previstas en el sistema ordinario de fuentes para situaciones extraordinarias).

Pues bien, históricamente la doctrina ha empleado un criterio de graduación (de menor a mayor gravedad, alarma, excep- ción y sitio) combinado con dualidades: las causas naturales motivarían el estado de alarma (no se pone en peligro la vida del Estado), y las políticas, los de excepción y sitio (que ponen en peligro la existencia misma del Estado). ${ }^{5}$

Sin embargo, estos criterios se han mostrado insuficientes debido a cuatro motivos: a) porque ni en la ley ni en la Constitución se emplea ese criterio (que fuese esa la intención no implica que el tenor literal la reflejase); b) porque un evento natural (un asteroide gigantesco) podría provocar también consecuencias políticas (la "muerte" del Estado), y un evento político, consecuencias naturales (v. gr. un golpe de estado que provoca un accidente nuclear). De hecho, algo así es lo que ha sucedido: la pandemia ha impedido la libre circulación, las reuniones, las manifestaciones y la celebración de elecciones; c) porque el criterio reproduce un mito procedente de la teología cristiana, la distinción entre el Reino de la Naturaleza y el Reino de la Cultura (que antes era de la Gracia 6 ). Esto es, presupone que hay dos mundos diferenciados, el de la Naturaleza y el de la Política (adaptación

5. A raíz de la huelga de controladores, Aba resumió la posición de la doctrina en el sentido que hemos citado (Aba, 2011). Como consecuencia de la pandemia, ilustres juristas como Pérez Royo (en Guindal, 2020), o Cruz Villalón (2000a) también hicieron hincapié en la adecuación del estado de alarma ante la pandemia debido a que estábamos ante una situación causada "por la naturaleza" y "no por el hombre". También se analiza esta dicotomía en García de Enterría (2020), Todo ello sin perjuicio de que otros autores defiendan que "ninguno de los estados previstos en el artículo 116 CE se adecúan a las circunstancias concurrentes" (García de Enterría, 2020).

6. Véase Bueno, Gustavo (1996): El mito de la cultura. Pentalfa ediciones. 
del Reino de la Cultura), como compartimentos estancos merecedores de legislaciones separadas; d) porque en la única aplicación práctica que hemos vivido, las causas (pandemia) se han superpuesto con los efectos (suspensión de facto de derechos constitucionales).

En este sentido, el Tribunal Superior de Justicia de Aragón, a raíz de que se pronunciara sobre si los derechos de manifestación y reunión habían quedado suspendidos de facto durante el estado de alarma, cuestionó directamente que se hubiese empleado un criterio meramente nominalista (si es epidemia, es que se necesita un estado de alarma) y no tuviese en cuenta los derechos realmente afectados por las necesidades de la crisis de la pandemia, esto es, los efectos:

Cabe plantearse de manera más que razonable que una situación de crisis sanitaria como la que sufrimos en estos momentos, puede implicar de facto una tan grave alteración del libre ejercicio de los derechos y libertades de los ciudadanos, o del normal funcionamiento de las instituciones, que haga razonable pensar que la herramienta más adecuada para el restablecimiento de tal normalidad de ejercicio pueda ser el estado de excepción. Y ello por encima de una tesis meramente nominalista -desacertada en su elección a nuestro juicio de haber sido tal el único criterio para ello-, que asocia el estado de alarma como herramienta indicada para el tratamiento de este tipo de situaciones, con idéntico propósito de vuelta a la normalidad, sin plantearse que la elección de la herramienta pueda tal vez exigir su acomodación a la envergadura de la crisis, previo examen de la misma.?

7. Tribunal Superior de Justicia de Aragón. Sala de lo Contencioso-Administrativo. Sección primera. Sentencia núm. 151/2020, de 30 de abril. RJCA 2020/474.
Como podemos observar, este tribunal pone en duda la adecuación del silogismo nominalista (si epidemia, entonces alarma; pandemia, luego alarma), planteando que el criterio adecuado debe ir en función de los derechos afectados (como examinaremos después, tampoco este criterio es demasiado afortunado) por una situación de anormalidad, no por las causas que la provocan.

Abundando en esta idea (la superposición de causas y efectos), la pandemia obligó a retrasar las elecciones en País Vasco y Galicia. Pues bien, no puede resultar más ilustrativo el contenido del decreto gallego de suspensión de las elecciones: ${ }^{8}$

Las medidas adoptadas, tanto a nivel nacional como autonómico, con el objetivo de luchar contra el COVID-19, conllevan, por tanto, serias restricciones de la movilidad y del ejercicio de actividades, así como de la apertura de establecimientos y locales. Estas medidas, necesarias para la protección de la salud pública, resultan, con todo, incompatibles con el normal desarrollo de un proceso electoral $y$, por tanto, del libre y normal ejercicio del derecho de sufragio (...) además de que las medidas relativas a la limitación de la libertad de circulación de personas impedirían, asimismo, el desarrollo de la jornada electoral con las garantías que el derecho fundamental de sufragio impone. (...) el derecho de sufragio es el derecho fundamental que encarna el derecho de participación política en el sistema democrático de un Estado social y democrático de derecho, que consagra el artículo 1 de la Constitución española y es la forma de

8. La efectividad del Decreto 2/2020, de 10 de febrero, que disolvió el Parlamento Vasco y convocó elecciones para el día 5 de abril de 2020, tuvo que suspenderse mediante Decreto 7/2020, de 17 de marzo, basándose en argumentos similares. 
ejercer la soberanía que el mismo precepto consagra (Nota: las cursivas son mías). ${ }^{9}$

Resulta indiscutible que el contenido de este decreto de suspensión coindice más con la forma en que está redactado el estado de excepción (grave alteración del funcionamiento de las instituciones democráticas) que con el de alarma, entre otras cosas, porque el decreto de alarma ni siquiera se planteó suspender las elecciones autonómicas porque no resulta lícito con esta figura jurídica. Desde esta perspectiva, y atendiendo precisamente a la Ley $4 / 81$, la pandemia nos introdujo en un terreno no hollado previamente: el estado de alarma formal explicaba por qué estábamos en un estado de excepción de facto.

En conclusión, atribuir el causalismo al estado de alarma y el consecuencialismo al de excepción evita enfrentarse a una hipotética superposición de ambos estados (una causa prevista en el estado de alarma que genera las consecuencias previstas en el estado de excepción), de ahí que deba ser desechado en el futuro debido a que no ha resistido una (única) confrontación de la teoría con los hechos.

\subsection{Por criterios cuantitativos}

El artículo 11 de la Ley 4/1981 establece cuatro medidas posibles a adoptar durante un estado de alarma. Nos interesa destacar el apartado "a", ya que permite "Limitar la circulación o permanencia de personas o vehículos en horas y lugares determinados, o condicionarlas al cumplimiento de ciertos requisitos".

9. Decreto 45/2020, de 18 de marzo, por el que se deja sin efecto la celebración de las elecciones al Parlamento de Galicia de 5 de abril de 2020 como consecuencia de la crisis sanitaria derivada del COVID-19.
En el estado de excepción, el artículo 13.2 permite la suspensión de uno, varios o todos los derechos enumerados en el artículo 55.1 de la Constitución española. Del listado, destacamos la libertad de circulación y residencia (art. 19); los derechos de reunión y manifestación (art. 21); el derecho de huelga (art. 28.2); y el derecho a la adopción de medidas de conflicto colectivo (art. 37.2).

En puridad, el estado de excepción no tiene por qué ser más restrictivo que el estado de alarma. Imaginemos que simplemente se suspende el derecho a adoptar medidas de conflicto colectivo por una alteración del orden público. Obviamente, durante el estado de alarma hemos padecido restricciones muy superiores a las que podrían provocarse por la suspensión de las medidas de conflicto colectivo, que no solo afectaría a una parte de la población (los trabajadores por cuenta ajena), sino que no es un derecho susceptible del recurso de amparo ante el Tribunal Constitucional y ni tan siquiera requiere una ley orgánica para su regulación. Es decir, resulta un derecho claramente "menor" frente a, por ejemplo, la libertad de circulación, entre otras cosas, porque no pertenece al grupo de los "derechos fundamentales y las libertades públicas", (sección primera del capítulo segundo de la Constitución), sino a los "derechos y deberes de los ciudadanos" (sección segunda).

Por otra parte, la legislación ordinaria también puede ser más restrictiva que el propio estado de excepción. Aunque lo comentaremos, por claridad expositiva, más adelante, durante el estado de alarma los tribunales de justicia estimaron que podía suspenderse el derecho de manifestación y/o el de reunión, no por el decreto de alarma (que nada preveía), ni por el estado de excepción (que no se había de- 
cretado), sino por la legislación ordinaria que posibilita la suspensión de derechos constitucionales en determinados casos. De ahí que las denegaciones de manifestación y reunión de las delegaciones del gobierno pudieran impugnarse ante la jurisdicción ordinaria (si hubiesen formado parte del estado de alarma, solo el Tribunal Constitucional habría podido entrar a conocer), porque durante la pandemia se suspendieron derechos constitucionales con la cobertura jurídica del sistema de fuentes de la legislación ordinaria.

Por ello, es una falacia sostener que las restricciones de derechos durante un estado de excepción son más gravosas que durante un estado de alarma, ya que incluso el sistema de fuentes ordinario puede establecer más limitaciones que el propio sistema de fuentes del derecho de excepción. Todo dependerá de qué derechos en concreto se limiten o suspendan, sin que a priori podamos decidir qué estado, excepción o alarma, es más restrictivo o lesivo para el conjunto de los ciudadanos. Si durante un estado de excepción se suspende el derecho a la adopción de medidas de conflicto colectivo, y durante una situación de anormalidad sanitaria, pero de normalidad jurídica, se suspende el derecho de manifestación y/o reunión, no cabe sostener que aquel estado, el de excepción, sea más restrictivo que este.

En conclusión, la dicotomía "alarma" vs "excepción" no puede resolverse de forma cuantitativa a priori, por cuanto la cantidad de derechos, en el sentido numérico de la expresión, dependerá de las necesidades de la situación concreta y de la forma en que se redacte la norma que declare dicho estado, hasta el punto de que una situación de normalidad jurídica pero de anormalidad fáctica (pandemia) puede ser más restrictiva cuantitativa- mente (v. gr., número de derechos afectados) para los derechos fundamentales que el propio estado, no ya de alarma, sino incluso de excepción.

\subsection{Por criterios cualitativos}

La principal diferencia entre el estado de alarma y el de excepción parece venir dada por un criterio meramente cualitativo, esto es, de intensidad. Para ello, se emplea en este caso otra dualidad, limitación/suspensión. ${ }^{10}$

En efecto, durante el estado de alarma los derechos se "limitan", mientras que durante un estado de excepción los derechos se "suspenden".

Si atendemos al significado del DRAE, nos encontramos con que "limitar" significa, en su tercera acepción, "fijar la extensión que puede tener la autoridad o los derechos y facultades de alguien", mientras que "suspender", en su segunda acepción, es "Detener o diferir por algún tiempo una acción u obra"

El Diccionario no nos resulta de demasiada utilidad para una interpretación jurídica, pero aun así cabe sostener que "suspender" implica impedir temporalmente, pero de forma total y absoluta, uno o varios derechos (v. gr., derecho de huelga), mientras que "limitar" supone restringir parcialmente el ejercicio de uno o varios

10. Como nos recuerda Álvarez (2020) "En este punto hay que centrar la cuestión en la diferencia entre limitación o `restricción del derecho fundamental, y suspensión del mismo, aun partiendo del dato de que, como apunta el TEDH, entre 'privación' y 'restricción de libertad' no hay más que una diferencia de grado o de intensidad, no de naturaleza o de esencia (Caso Guzzardi contra Italia de 6 de noviembre de 1980 y caso Amuur contra Francia de 25 de junio de 1996; (...)”. 
derechos (v. gr., se puede ejercer el derecho de manifestación, pero no en plenitud, como puede ser manifestarse en coche guardando la distancia de seguridad).

Ahora bien, para valorar cuál de las dos situaciones es más gravosa, limitar o suspender, habrá que estar a cada concreto. Si se trata de un único derecho (v. gr., huelga), es obvio que el estado de excepción es más gravoso (impediría la huelga) que el de alarma; pero entre suspender un único derecho (v. gr., medidas de conflicto colectivo) y limitar varios derechos fundamentales (manifestación, reunión, libertad de circulación), parece también obvio que con el estado de alarma se puede perjudicar más el ejercicio de los derechos básicos que con el estado de excepción. Todo dependerá de qué derechos en concreto entren en juego.

E incluso ante un mismo derecho, no resulta fácil defender cuándo se ha limitado y cuándo se ha suspendido; menos aún, cómo valorar la limitación de un derecho que constituye una conditio sine qua non para el ejercicio de otros,

Un voto particular en el Tribunal Superior de Justicia de Aragón reflexionaba sobre la conexión entre los derechos a partir de dos datos: a) durante el estado de alarma, no se puede suspender ningún derecho; c) pero si el estado de alarma limita (prohíbe) la libre circulación, está suspendiendo de facto derechos como el de reunión y manifestación (el decreto de alarma permitía salir a la calle en algunos casos, pero no lo permitía para manifestarse ni reunirse). Por ese motivo, el magistrado discrepante con sus compañeros estimaba que no se debía entrar en el fondo del asunto y que resultaba necesario plantear una cuestión de constitucionalidad para que el Tribunal Constitucional se pronunciara sobre cómo la limitación casi absoluta del derecho a la libre circulación estaba suspendiendo de facto los derechos de reunión y manifestación. ${ }^{11}$

El voto mayoritario sí decidió entrar en el fondo del asunto, pero aun así se planteó una objeción similar, básicamente, la posible inconstitucionalidad del estado de alarma atendiendo a que el derecho a la "libre circulación" había quedado suspendido de facto:

(...) y ello con independencia de la más o menos cuestionable constitucionalidad del mentado artículo 7 (del Real Decreto de alarma) por razón de la intensidad de la afectación que, a la luz del artículo 11a) de la LO 4/1981, de 1 de junio (RCL, 1981, 1291) de los estados de alarma, excepción y sitio, impone de facto a la libre circulación de los ciudadanos, intensidad de la que, dicho sea de paso, es muestra el uso, ya asumido cotidianamente con naturalidad, de términos como "confinamiento" o "encierro", que evocan más abolición o suspensión, que limitación de ejercicio, actitud esta -limitación- más propia de un estado de alarma que aquella- confinamiento-. ${ }^{12}$

El problema de fondo que planteó esta sentencia es que, al bloquearse un derecho, llámesele restricción o limitación, o como se quiera, se están suspendiendo de facto otros que no podían ser suspendidos bajo ningún caso. ¿Cómo valorar una situación en la que el ciudadano tiene derecho a manifestarse junto a otros ciudadanos, pero al mismo tiempo no puede salir de casa si no es para ir al supermercado, la farmacia o sacar a pasear a un perro? Sin derecho a la libre circulación

11. Tribunal Superior de Justicia de Aragón. Sala de lo Contencioso-Administrativo. Sección primera. Sentencia núm. 151/2020, de 30 de abril. RJCA 2020/474.

12. Idem. 
se impedía el derecho de reunión y/o de manifestación, así como otros de ejercicio social (v. gr., de contenido religioso). Unos derechos presuponen otros, de ahí que no puedan fragmentarse racionalmente (v. gr., derecho a la vida como precondición de los demás: libertad de circulación como precondición del derecho a manifestarse o reunirse; etc.).

Desde esta perspectiva, el problema nos reenvía al cálculo infinitesimal (v. gr., paradoja de Aquiles y la tortuga). Si un ciudadano no podía salir del perímetro donde radica la farmacia o el supermercado de su barrio, ¿estábamos ante una limitación $\mathrm{o}$ ante una suspensión de derechos? E ciudadano está "limitado" a su barrio, en efecto, e inevitablemente "suspendido" más allá de dicho perímetro (si sale, lo detiene la policía; y si reitera la salida, entonces es acusado de desobediencia).

Si de cien ítems de ejercicio que pueda contener un hipotético derecho (salir de casa, del barrio, de la provincia, de la comunidad autónoma, a pasear, a trabajar, a comprar, etc., recordemos que no es un ejercicio teórico, todas estas restricciones han existido), se limitan noventa y nueve, ¿sigue siendo un estado de alarma? Si un ciudadano no puede salir de su provincia, disfruta, en efecto, de la libre circulación dentro de la misma, pero al mismo tiempo tiene suspendida la libre circulación en otra provincia. La limitación de un derecho conlleva la suspensión de ese mismo derecho en un plano temporal o espacial diferente, de ahí que no quepa fijar una frontera nítida entre el estado de alarma y el de excepción empleando este criterio dual.

Por otra parte, el artículo 26 de la Ley 4/81, sobre el estado de excepción, establece que:

Uno. La Autoridad gubernativa podrá ordenar la intervención de industrias o comercios que puedan motivar la alteración del orden público o coadyuvar a ella, y la suspensión temporal de las actividades de las mismas, dando cuenta a los Ministerios interesados.

Dos. Podrá, asimismo, ordenar el cierre provisional de salas de espectáculos, establecimientos de bebidas y locales de similares características.

Resulta indiscutible que estos dos hechos ocurrieron durante el estado de alarma, tanto durante la fase más laxa como en el periodo más restrictivo de la primera quincena de abril. En este segundo periodo no solo se prohibió la actividad empresarial, comercial o profesional, sino que para frenar la curva de contagio se paralizó expresamente la actividad industrial, incluida la construcción. Por otra parte, bares, cines, teatros, etc., estuvieron cerrados durante todo el periodo de alarma, salvo al final de la fase de desescalada. La mejor forma de comprender cómo lo vieron los propios juristas y políticos es citar el decreto de suspensión de las elecciones de Galicia:

Entre las medidas previstas en el real decreto se encuentran fuertes restricciones a la libertad de circulación de personas, la suspensión de la apertura al público de buen número de locales y establecimientos en el ámbito de la actividad comercial, equipamientos culturales, establecimientos y actividades recreativas, actividades de hostelería y restauración, y otras adicionales, así como la ratificación de las medidas autonómicas y locales ya adoptadas en relación con el coronavirus COVID-19 que sean compatibles con las previstas en el Real Decreto. ${ }^{13}$ (Nota: las cursivas son mías).

El ilustre jurista Cruz Villalón (2020b) reconoce que lo sucedido durante el segundo periodo de alarma (la fase más dura, entre el 30 de marzo y el 9 de abril) enca-

13. Op. Cit. Decreto 45/2020. 
jaba jurídicamente menor en el estado de excepción que en el de alarma (aun así, siguió sosteniendo que lo procedente era el estado de alarma).

En conclusión, tal y como sucede con el criterio anterior, resulta una falacia sostener que el estado de excepción es más gravoso para una democracia que el estado de alarma por la intensidad en que quedan afectados los derechos (suspensión vs limitación). A priori no podemos decidir si es peor suspender un derecho o limitar varios; por otra parte, los derechos están conectados, de forma que la limitación de unos (libre circulación) supone de facto la suspensión de otros (manifestación y reunión); por último, hay que hacer verdaderos malabarismos dialécticos para sostener que durante el estado de alarma determinados derechos, como el de libre circulación o la posibilidad de abrir comercios, etc., estuvieron limitados y no suspendidos. El principio in dubio pro ciudadano nos debe llevar a aceptar que, ante la duda, determinados derechos han sido suspendidos, ya que interpretar que fueron meramente limitados beneficia a quien los limitó, el poder ejecutivo, lo que nos reenvía al siguiente criterio.

\subsection{En función del grado de control parlamentario}

Para declarar el estado de alarma, el poder ejecutivo no necesita la autorización del legislativo. Esto es, el Gobierno puede declarar el estado de alarma durante quince días mediante un decreto. La intervención del Congreso solo resulta necesaria para controlar, políticamente y a posteriori, su oportunidad, pero no su validez, ${ }^{14}$ o para

14. "Se trata, en todo caso, de una intervención de la Cámara a posteriori, una vez que ha tenido prorrogar dicho estado, que "en este caso podrá establecer el alcance y las condiciones vigentes durante la prórroga" (art. 6 de la Ley 4/81).

Por el contrario, para declarar el estado de excepción el Gobierno ha de solicitar autorización previa al Congreso de los Diputados (art. 13.2 de la Ley 4/81), detallando "los efectos del estado de excepción, con mención expresa de los derechos cuya suspensión se solicita" (letra "a"), así como la "Relación de las medidas a adoptar referidas a los derechos cuya suspensión específicamente se solicita" (letra "b"). El Congreso puede no solo rechazar la aprobación, sino también "introducir modificaciones" no previstas o que incluso contradigan la solicitud del Gobierno. ${ }^{15}$

Desde el punto de vista del ciudadano, el estado de excepción no solo no es más restrictivo que el estado de alarma (dependerá, como hemos expuesto, de los derechos en concreto que se limitan o suspendan), sino que, sobre todo, es más garante de sus derechos. En efecto, lo

lugar la declaración gubernamental del estado de alarma, y de naturaleza estrictamente política, esto es, que su resultado, si la intervención parlamentaria se llegase a concretar o formalizar en algo, no vincula jurídicamente al Gobierno, ni condiciona ni altera, por lo tanto, el contenido del decreto por el que se ha llegado a cabo la declaración del estado de alarma". Tribunal Constitucional. (Pleno). Sentencia núm. 83/2016 de 28 de abril.

15. En este sentido es preciso matizar una cierta superposición existente entre ambas figuras, ya que, en el decreto de alarma, la prórroga del parlamento no se limita a un mero "todo o nada", sino que también puede rechazar las medidas del gobierno y establecer otras " (...) bien haciendo suyos los propuestos por el Gobierno en la solicitud de prórroga, bien estableciéndolos directamente". Tribunal Constitucional. (Pleno). Sentencia núm. 83/2016 de 28 de abril. 
relevante es que el estado de excepción conlleva más seguridad jurídica (v. gr., por eso la solicitud al Congreso debe contener una relación detallada de los derechos a suspender), mientras que en el estado de alarma las restricciones quedan más indefinidas y al albur del ejecutivo.

Desde esta perspectiva, parece como si "limitar" los derechos fuese un cheque en blanco (ni siquiera hay un listado de los derechos a limitar, y menos aún existe un control a priori del legislativo). Los primeros quince días de un estado de alarma no son controlados propiamente por el Congreso, ya que su intervención a posteriori no afecta a la validez de dicho estado de alarma, mientras que la suspensión de los derechos, aunque sea uno solo y ni siquiera cuente entre los fundamentales (v. gr. las medidas de conflicto colectivo), exige un mayor rigor formal, que a la postre protege con mayor pulcritud a los ciudadanos. Parece obvio que el Gobierno cuenta con más margen de maniobra y discrecionalidad en el estado de alarma, sin control a priori del Congreso, de ahí que resulte tentador apoyarse en dicho estado para no sufrir un bloqueo parlamentario.

En conclusión, el estado de alarma favorece más al Gobierno, que puede adoptar medidas sin control parlamentario o con un control más laxo; y a la inversa, el estado de alarma perjudica más al ciudadano, que se puede ver sometido a una mayor inseguridad jurídica acerca del alcance del ejercicio de sus derechos.

\subsection{En función de la jurisdicción competente}

La comparación entre los estados de alarma o excepción, de un lado, y una situación de normalidad desde el punto de vista legal, pero anormal desde un punto de vista fáctico, incide no solo en los derechos limitados o suspendidos, sino sobre todo en el control jurisdiccional de las medidas adoptadas.

En efecto, en este criterio lo reseñable es que, durante el estado de alarma, las normas y actos emitidos por el Gobierno gozan del rango de ley y por tanto se sustraen al control por parte de la jurisdicción ordinaria.

Como ya hemos comentado, en una situación de normalidad jurídica se pueden adoptar medidas que supongan una restricción de derechos superior a la que se puede acordar durante un estado de alarma. Pero, por el contrario, el control jurisdiccional sigue perteneciendo a la jurisdicción ordinaria.

Así, mientras que los actos y normas dictados por el Gobierno durante el estado de alarma se sustraen al control de los tribunales ordinarios, incluido el Tribunal Supremo, (que en numerosas resoluciones se abstuvo de conocer), la aplicación de la legislación ordinaria permitió a los ciudadanos impugnar las resoluciones de las delegaciones del gobierno durante la pandemia, que le impedían manifestarse o reunirse, y entrar en el fondo del asunto a los tribunales de justicia.

De hecho, esto es lo que sucedió. La pandemia coincidió con una fecha tan emblemática como el 1 de mayo y se solicitaron permisos para manifestarse, en un contexto que indirectamente afectaba a la libertad sindical.

Las resoluciones de los juzgados fueron dispares. Así, las delegaciones del gobierno perdieron el pleito en Aragón; ${ }^{16}$

16. Tribunal Superior de Justicia de Aragón. Sala de lo Contencioso-Administrativo. Sección pri- 
León ${ }^{17}$; Valladolid, ${ }^{18}$ Soria ${ }^{19}$ y Barcelona. ${ }^{20}$ En Extremadura, el TSJ de Extremadura denegó un determinado tipo de manifestación, pero admitió otra modalidad, con más garantías, que se había solicitado de forma subsidiaria. ${ }^{21}$ Por el contrario, las delegaciones del gobierno ganaron el juicio en Navarra, ${ }^{22}$ Extremadura, ${ }^{23}$ Madrid (dos veces ${ }^{24}$ ) y Galicia. ${ }^{25}$

En todos estos casos se discutía si la pandemia permitía reunirse y manifestarse, dando por supuesto que el estado de alar-

mera. Sentencia núm. 151/2020, de 30 de abril. RJCA 2020/474.

17. Tribunal Superior de Justicia de Castilla y León. Valladolid. Sala de lo Contencioso-Administrativo. Sección 1 $1^{\text {a }}$. Sentencia núm. 462/2020 de 21 de mayo. RJCA 2020/586

18. Tribunal Superior de Justicia de Castilla y León. Valladolid. Sala de lo Contencioso-Administrativo. Sección 1 $1^{\text {a }}$. Sentencia núm. 465/2020 de 21 de mayo. RJCA 2020/689.

19. Tribunal Superior de Justicia de Castilla y León. Sala de lo Contencioso-Administrativo. Sección 2a $2^{a}$. Sentencia núm. 467/2020, de 21 de mayo. Jur. 2020/184270.

20. Tribunal Superior de Justicia de Cataluña. Sala de lo Contencioso-Administrativo. Sección $3^{\text {a }}$. Sentencia núm. 1391/2020 de 22 de mayo.

21. Tribunal Superior de Justicia de Extremadura. Sala de lo Contencioso-Administrativo. Sección $1^{\text {a }}$. Sentencia 175/2020. JUR/2020/208845.

22. Tribunal Superior de Justicia de Navarra. Sala de lo Contencioso-Administrativo. Sección 5a. Sentencia núm. 70/2020 de 30 de abril. RJCA 2020/649

23. Tribunal Superior de Extremadura. Sala de lo Contencioso-Administrativo, de 12 de mayo de 2020. RJCA 2020,505.

24. Tribunal Superior de Justicia de Madrid, Sala de lo Contencioso-Administrativo. Sentencia núm. 198/2020, de 30 de abril. RJCA 2020/752 y núm. 199/2020, de 30 de abril.

25. Tribunal Superior de Justicia de Galicia, Sala de lo Contencioso Administrativo de 28 de abril de 2020. Sentencia 136/2020. RJCA, 2020, 457. ma no había (no podía haber) suspensión de estos derechos. Pero el problema es más complejo, ya que el decreto del estado de alarma limitó el derecho a la libre circulación, sin el cual era imposible ejercer el derecho de manifestación y/o de reunión. De ahí que el sistema de fuentes de una situación de excepcionalidad, (no controlable por la jurisdicción ordinaria) se superpuso al sistema de fuentes ordinario previsto para situaciones excepcionales (controlable por la jurisdicción ordinaria). Lógicamente, la confusión argumentativa fue enorme. Quien mejor ejemplifica la perplejidad fue el Tribunal Superior de Justicia de Galicia. ${ }^{26}$

En efecto, el alto tribunal gallego fue el único que: a) estimó que el artículo 7 del decreto del estado de alarma legitimaba a las delegaciones del gobierno a impedir el ejercicio de manifestación y reunión, desechando incluso, en este caso, la posibilidad de interponer un recurso de inconstitucionalidad; b) a pesar de este presupuesto, denegó la manifestación porque los convocantes no ofrecían suficientes garantías para evitar el contagio (en un contexto, el gallego, donde el coronavirus estaba golpeando con especial letalidad), esto es, en base a la legislación ordinaria (colisión entre el derecho a la vida, a la salud y a la integridad física, frente al derecho de libre manifestación y reunión); c) fue el único caso que acabó en el Tribunal Constitucional, pero este rechazó el recurso de amparo y perdió la oportunidad de aclarar cuál era el título que permitía impedir el derecho de manifestación ("no puede ser abordada, ni siquiera a efectos dialécticos en este momento procesal| ${ }^{27}$ ).

26. Ídem.

27. Auto del Tribunal Constitucional de 30 de abril de 2020 . 
La confusión alcanzó a la propia delegación del gobierno: "Ahora bien, la confusa y defectuosa redacción de la resolución de la Subdelegación del Gobierno puede generar cierta incertidumbre, pues, antes del contenido propiamente decisorio, en su primer párrafo hace constar que, ante la situación de emergencia sanitaria, no puede trasladar un criterio sobre la celebración de la manifestación" (las cursivas son mías), y, en palabras del propio alto tribunal, incluso a la propia fiscalía "La Sala considera que esta ponderación de bienes jurídicos en presencia es lo que se le escapa al Ministerio Fiscal en su dictamen (...)" (la fiscalía estaba a favor de que se celebrase la manifestación).

La propia fiscalía, si bien en otro asunto, participó de esta mezcla de títulos (ora estamos en estado de alarma, ora se aplica la legislación ordinaria prevista para situaciones extraordinarias) en su argumentación:

(...) es una temeridad la celebración de la manifestación planeada y prohibida ahora. Añade que el artículo 7 del RD 463/2020 no ha suspendido el derecho fundamental de manifestación, pero sí que ha limitado el ejercicio de la libre circulación de personas y vehículos por razón de crisis sanitaria, supuesto de hecho que ampara tales limitaciones. $^{28}$

Por otra parte, la relevancia de que el decreto de alarma crease su propio sistema de fuentes no susceptible de ser fiscalizado por los tribunales debe situarse en un contexto de intento, si bien minoritario, de abandono del ejercicio de las funciones jurisdiccionales.

28. Tribunal Superior de Justicia de Aragón. Sala de lo Contencioso-Administrativo. Sección primera. Sentencia núm. 151/2020, de 30 de abril. RJCA 2020/474.
En efecto, pasaron desapercibidas las propuestas de algunas administraciones autonómicas y de algunas asociaciones de jueces que habrían dejado a nuestro país sin justicia alguna. Por ello, el Consejo General del Poder Judicial tuvo que intervenir, mediante un comunicado, para alertar de la necesidad de mantener una actividad judicial, siquiera mínima, hubiese o no medios de protección.

Por otra parte, algunas asociaciones profesionales de jueces y magistrados han realizado comunicados condicionando la prestación de los servicios esenciales a la obtención previa de medios de protección individual y colectiva pese a la notoria limitación de recursos disponibles y a la existencia de otras prioridades como es la exigida por el servicio sanitario. ${ }^{29}$

El Consejo General del Poder Judicial apeló a la emotividad (Ios aplausos en los balcones a las ocho, pero en clave judicial) y puso como ejemplo al personal sanitario "sumando incluso los esfuerzos de profesionales jubilados y de jóvenes estudiantes de último año", a las fuerzas de seguridad y al personal privado de la cadena de abastecimientos de alimentos, para recordar que en ningún caso sería legitima la suspensión de la actividad judicial durante el estado de alarma ("planteamientos o propuestas de abandono de servicio que difícilmente podían ser compartidas ni comprendidas por la ciudadanía"), si bien las asociaciones mayoritarias y algunos jueces a título individual se desmarcaron de este intento de deserción.

Por último, la relevancia de la jurisdicción ordinaria durante el estado de alarma se

29. Consejo General del Poder Judicial. Comunicado en relación con la prestación de servicios esenciales en el ámbito de la Administración de Justicia. Marzo de 2020. 
pone de manifiesto si recordamos que la creación de un sistema de fuentes alternativo intentó ser aprovechada por algunas administraciones autonómicas para suspender derechos que nada tenían que ver con la alarma, o incluso "devolver" competencias al Estado (que no habían sido reclamadas). Así, la Comunidad Autónoma de Castilla y León entendió que la libertad sindical y la negociación colectiva habían quedado suspendidos por "la urgencia representada por la actual situación excepcional", amparándose en el decreto de alarma. Perdió el juicio y fue condenada en costas; ${ }^{30}$ la Comunidad Autónoma de Castilla y León entendió que el Decreto de alarma suspendía sus competencias sobre seguridad y salud del personal sanitaria. Perdió el incidente procesal (solicitud de medidas cautelarísimas) y fue condenada a proporcionar medios adecuados al personal sanitario que, como sostenía el auto del juzgado "es notorio (exento de prueba), que los trabajadores del ámbito de la salud están prestando servicios esenciales y valiosos para la población, con un ejemplar sacrificio, y con exposición al riesgo de contagio (...)". ${ }^{31}$

En resumidas cuentas, en vez de declarar el estado de excepción, que hubiese proporcionado seguridad jurídica a los ciuda-

30. Juzgado de lo Contencioso-Administrativo número 1 de Valladolid. Sentencia núm. 52/2020 de 4 de junio. RJCA 2020/694.

31. Juzgado de lo Social de Ávila. Auto de 7 de abril de 2020. AS 2020/1420. En un sentido similar, aunque "inaudita parte", el Tribunal Superior de Justicia del País Vasco (Sala de lo Social, Sección $1^{a}$ ). Auto de 3 de abril de 2020, donde se citan, "por cortesía doctrinal y judicial", al menos catorce resoluciones judiciales de contenido análogo donde se requería a la administración para que suministrara material de protección a los colectivos, como los sanitarios especialmente desprotegidos. danos y a los tribunales acerca de qué derechos estaban suspendidos, se optó por un estado de alarma que, en unos casos se extendió más de lo que resultaba lícito (suspendió de facto la libre circulación) y en otros fue insuficiente (no suspendió, porque no podía, los derechos de manifestación y/o reunión), obligando a los tribunales de justicia a hacer verdaderos malabarismos para romper la conexión entre la libre circulación (no sujeta a su control jurisdiccional, por figurar en el estado de alarma) y el derecho de manifestación y/o reunión (sí sujeto a su control jurisdiccional, porque se suspendía con la legislación ordinaria), ya que sin la primera no se podía ejercer la segunda. Y todo ello en un contexto en el que la jurisdicción ordinaria estuvo a punto de suspenderse en el pleno sentido de la expresión. Por ello, lo realmente determinante para diferenciar al sistema de fuentes del derecho de excepción del sistema ordinario de fuentes reside en la sustracción a la jurisdicción ordinaria de las normas dictadas al amparo de aquel (estado de alarma, en nuestro caso), consecuencia del cambio en la naturaleza de dichas normas, que pasan a gozar del rango de ley, matiz que analizaremos a continuación.

\subsection{En función del rango de las normas dictadas}

Como hemos expuesto, las normas dictadas por el Gobierno adquieren el rango de ley. Ahora bien, nunca habíamos asistido a un periodo tan prolongado ni generalizado de alarma, lo que suscita numerosas dudas acerca de la naturaleza última de las diferentes normas que se han dictado durante dicho estado de alarma. Además, para desconcierto de los juristas, durante la pandemia se han simultaneado ambos 
sistemas de fuentes, el ordinario y el del derecho de excepción, hasta el punto de dictarse también normas ordinarias con rango de ley cuyo estatuto no sabemos si pertenecen realmente a un sistema de fuentes o al otro, o a ambos a la vez. Lo mismo ha sucedido con algunos actos de naturaleza no jurídica emanados del Gobierno.

Pues bien, para poder valorar adecuadamente el estado de alarma desde el punto de vista del rango de las normas, hemos de reconducir este, no a sus normas y sucesivas prórrogas (entre el 15 de marzo y el 21 de junio), sino a la forma en que los derechos fundamentales se vieron restringidos. Desde esta perspectiva, podemos distinguir tres fases. La primera fue entre el 15 y el 29 de marzo, y el 10 y el 24 de abril (estado de alarma débil); la segunda fase se desarrolló entre el 30 de marzo y el 9 de abril (estado de alarma fuerte); y la tercera entre el 25 de abril y el 21 de junio (proceso de desescalada). Es preciso realizar esta distinción, ya que los efectos legales y el sistema de fuentes empleado fueron muy diferentes.

El primer estado de alarma (débil) confinó a la población, pero mantuvo una cierta actividad económica. Tuvo dos periodos, el primero, entre el 15 y el 29 de marzo, y el segundo, entre el 10 de abril y el inicio de la desescalada, 24 de abril (entre ambos periodos, se vivió el confinamiento más estricto que analizaremos después).

Este primer periodo no presenta especiales problemas desde el punto de vista de las fuentes del derecho. El decreto que declara el estado de alarma (dictado por el Gobierno, no en calidad de órgano superior de la administración, sino como órgano constitucional), los actos parlamentarios de autorización de la prórroga y los decretos de prórroga gozan del carácter de "rango de ley", "fuerza de ley" o "valor de ley" "idéntica condición ha de postularse, pese a la forma que reviste, de la decisión gubernamental de prórroga, que se limita a formalizar y exteriorizar el acto parlamentario de autorización" TC 83/16). Además, el decreto que declara el estado de alarma supone una suspensión del sistema ordinario de fuentes, de forma que, sin derogar ni modificar las leyes, puede excepcionar su aplicación durante un tiempo. ${ }^{32}$ Los tribunales ordinarios quedan obligados por su contenido, dado que estas normas solo pueden impugnarse indirectamente, mediante una cuestión de constitucionalidad. ${ }^{33}$

El "segundo" estado de alarma, que hemos denominado "fuerte" por contraposición al anterior, "débil", se adoptó entre el 30 de marzo y 9 de abril, y fue el más duro. No solo se mantuvo el confinamiento de la población, con especial referencia a los niños, sino que se paralizó toda actividad económica no esencial. Es preciso recordar que la curva de contagios y fallecidos creció dramáticamente durante la segunda quincena del mes de marzo, hasta alcanzar casi mil muertos al día. Por ello, el Gobierno decidió aumentar el nivel de confinamiento prohibiendo toda activi-

32. En este sentido, conviene recordar que la doctrina duda acerca de la naturaleza de los Reales Decretos que dan lugar a un estado de alarma, asignándole una naturaleza dual “(...) el sentido y eficacia de tales Reales Decretos son complejos y no reconducibles exclusivamente al propio de las normas jurídicas" citando a Garrido López, quien sostiene que "Materialmente, las decisiones excepcionales del art. 116 son, por tanto, mitad actos y mitad normas" González, (2020).

33. Real Decreto 463/2020, de 14 de marzo, por el que se declara el estado de alarma para la gestión de la situación de crisis ocasionada por el COVID-19. 
dad profesional, laboral o empresarial que no fuese imprescindible. Esto paralizó la industria, incluida la construcción.

Ahora bien, el sistema de fuentes empleado para restringir aún más la movilidad no fue el del derecho de excepción, sino el sistema ordinario de fuentes, en concreto, un decreto-ley que obligó a los trabajadores a disfrutar de un permiso retribuido.

En efecto, el Real Decreto-Ley 10/2020, de 29 de marzo, que paralizó toda actividad no esencial en España, reguló un permiso retribuido recuperable para las personas trabajadoras por cuenta ajena que no prestaran servicios esenciales, con el fin de reducir la movilidad de la población en el contexto de la lucha contra el COVID-19. Esto es, en vez de "suspender" el derecho al trabajo, se les concedía un permiso remunerado, a pesar de que se estaba suspendiendo tanto el derecho al trabajo (cobrar sin trabajar puede ser incluso motivo de resolución voluntaria del trabajador por incumplimiento de la empresa, artículo 50 del Estatuto de los Trabajadores), como lo que realmente se buscaba, limitar la libre circulación (los trabajadores de la industria cayeron inmediatamente bajo el ámbito de aplicación del decreto de alarma), esto es, afectó a los derechos, deberes y libertades del título I de la Constitución española, algo expresamente prohibido en su artículo 86. ${ }^{34}$

Además, a diferencia del Real Decreto de 14 de marzo que inició el estado de alarma ("debil"), el Real Decreto-Ley aprobado el 29 de marzo ("fuerte"), como si

34. Por supuesto, en el propio Real Decreto se establecía que no afectaba a los "derechos, deberes y libertades del título I". Huelga recordar en qué título de la Constitución aparecen citados el derecho al trabajo, a la negociación colectiva o a las medidas de conflicto colectivo. de espantar la mala conciencia se tratase, trató de justificar su aprobación ("Los motivos de oportunidad que acaban de exponerse demuestran que, en ningún caso, el presente real decreto-ley constituye un supuesto de uso abusivo o arbitrario de este instrumento constitucional"). ${ }^{35}$ Este Real Decreto se justificó alegando que: a) se trataba de una decisión política; b) y que no daba tiempo a que interviniese el parlamento.

Ninguno de estos dos requisitos, decisión política e imposibilidad de reunir el parlamento, aparecen en la Ley 4/1981, que ya hemos examinado, como criterio de distinción entre los estados de alarma y de excepción. La diferencia entre ambos no reside en una decisión sujeta a discrecionalidad del poder ejecutivo porque no dé tiempo a reunir al legislativo. De hecho, en el Real Decreto de 14 de marzo, con el que se comenzó el estado de alarma débil, la justificación del mismo era que este instrumento no resultaba tan lesivo para los derechos de los ciudadanos como el de excepción (limitación versus suspensión de derechos). Ahora, el 29 de marzo, sin salirse del estado de alarma, pero sin entrar en el de excepción, se dio una vuelta de tuerca en la restricción de derechos, pero apelando, no ya a la menor restricción de derechos (ya no se podía hablar de "limitación" del derecho al trabajo o a la libre circulación), sino a un criterio de discrecionalidad política en un contexto tan urgente que no daba tiempo

35. Tanto el Real Decreto de alarma del 14 de marzo, como sus sucesivas prórrogas, contenían menos lapsus freudianos: "Las medidas que se contienen en el presente real decreto son las imprescindibles para hacer frente a la situación, resultan proporcionadas a la extrema gravedad de la misma y no suponen la suspensión de ningún derecho fundamental" 
siquiera a que el parlamento interviniera. Así lo podemos leer en el Real DecretoLey de 29 de marzo:

(...) el fin que justifica la legislación de urgencia sea subvenir a una situación concreta, dentro de los objetivos gubernamentales, que por razones difíciles de prever requiere una acción normativa inmediata en un plazo más breve que el requerido por la ley normal o por el procedimiento de urgencia para la tramitación parlamentaria de las leyes, máxime cuando la determinación de dicho procedimiento no depende del Gobierno. Asimismo, la extraordinaria y urgente necesidad de aprobar las medidas que corresponde al Gobierno (...) y esta decisión, sin duda, supone una ordenación de prioridades políticas de actuación (...) extraordinaria y urgente necesidad (...) los objetivos que se pueden alcanzar con el mismo no pueden conseguirse a través de la tramitación de una ley por el procedimiento de urgencia.

Como se puede observar, el Real Decreto-Ley de 29 de marzo se justifica por el estado de alarma, pero a la vez pretende no formar parte del sistema de fuentes del derecho de excepción. Por ello apela a criterios de oportunidad política y de temporalidad, incluso de autojustificación ("máxime cuando la determinación de dicho procedimiento -tramitación de una ley - no depende del Gobierno").

Desde un punto de vista estrictamente formal, el Real Decreto-Ley de 29 de marzo no formó parte de las fuentes del derecho de excepción (seguía vigente la del 14 de marzo, y estamos ante un Decreto-Ley, no ante un Real Decreto de alarma), sino una ampliación material de los efectos del Real Decreto del 14 de marzo; pero, y es un dato especialmente relevante, sin someterse siquiera a los requisitos establecidos por la Ley 4/1981. Es decir, el Gobierno suspendió el derecho a trabajar (afecta a la negociación colectiva) y la libre circulación mediante un Real Decreto-Ley que, aunque lo aprobase después el Congreso, se excedía en la materia que regulaba (derechos y deberes del título I, expresamente vedados a los decretos-leyes, art. 86.1 de la Constitución). Además, la prórroga del decreto de alarma por parte del Congreso es diferente a la convalidación de un decreto-ley. En ambos casos estamos ante normas con rango de ley, pero en el primer caso el Congreso puede introducir modificaciones sustanciales en el decreto de alarma, mientras que en el decreto-ley solo puede convalidarlo sin introducir matices. ${ }^{36}$ Este Real Decreto-Ley no podía ser considerado un "acto con fuerza de ley" en el sentido que lo establece el Tribunal Constitucional para el estado de alarma (TC 83/2016), ${ }^{37}$ pero sí una norma con fuerza de ley en el sentido que lo establece la Constitución, siempre y cuando, claro está, no se emplee para ampliar un estado de alarma...

En puridad, el permiso retribuido obligatorio solo se podía aprobar mediante el Real Decreto de alarma, formando parte del contenido del mismo y de la prórroga del Congreso (que puede modificar su contenido), pero no mediante un Real DecretoLey donde la intervención del Congreso se reduce a validarlo a posteriori, pero sin poder cambiar su contenido.

Otra posibilidad es asumir que el Decreto-Ley se dictó al amparo del sistema de

36. El Real Decreto-ley 10/2020, de 29 de marzo, fue convalidado por un Acuerdo del Congreso de los Diputados, publicado por Resolución de 9 de abril de 2020. Ref. BOE-A-2020-4426.

37. Tribunal Constitucional. (Pleno). Sentencia núm. 83/2016 de 28 de abril 
normas del derecho de excepción, pero entonces, ¿qué sentido tenía aprobar un Decreto-Ley, si bastaba con un Decreto? Si aceptáramos esta segunda hipótesis, tendríamos que afrontar el absurdo de que una norma emanada del Gobierno adquiría el rango de ley dos veces, una, en calidad de norma dictada al amparo del decreto de alarma, y otra, en calidad de decreto-ley convalidado por el Congreso (lo que se hizo el 9 de abril), ¿para qué convalidarlo, pues, si ya era una norma con rango de ley? Es más razonable, entonces, aceptar que el decreto-ley se dictó al amparo del sistema de fuentes ordinario, con todas las contradicciones que ello (también) conlleva.

En resumen: si la situación de la pandemia hacía aconsejable aumentar la restricción de la movilidad de los ciudadanos, esto es, limitar, restringir o incluso suspender el derecho a la libre circulación, el instrumento nunca podía ser un subterfugio (conceder permisos remunerados obligatorios mediante un Real Decreto-Ley que se excedía en su cometido), sino decretar el estado de excepción. En vez de hacerlo, se acudió al sistema de fuentes ordinario forzando sus reglas, hasta el punto de aprobar un Decreto-Ley que directa o indirectamente afectaba a los derechos fundamentales, algo vedado por el artículo 86 de la Constitución, introduciendo una norma, perteneciente al sistema ordinario de fuentes, en el sistema de fuentes del derecho de excepción, pero sin querer reconocerlo.

La tercera fase, la denominada "proceso de desescalada", fue aún peor desde el punto de vista normativo. Se regularon los derechos fundamentales de los españoles, en un inigualable proceso de degradación del rango jerárquico de las fuentes del derecho, mediante órdenes ministe- riales que reproducían miméticamente un plan del gobierno de naturaleza política.

En efecto, entre el 25 de abril y el 21 de junio, en un contexto de menor contagio y fallecimientos, se fue aumentando paulatinamente la posibilidad de salir a la calle. Sin embargo, la prudencia obligó a establecer franjas de horas, vinculadas a la edad, para poder ejercer el derecho a la libre circulación. Además, seguía restringida la movilidad no solo interprovincial, sino incluso la distancia a la que se podían alejar los ciudadanos de sus domicilios.

Pues, bien, la fase de desescalada comenzó con un documento de naturaleza ajurídica ("hoja de ruta"), aprobado por el Consejo de Ministros el 28 de abril. Este documento renunció expresamente a su carácter normativo ("El Plan para la Transición hacia una Nueva Normalidad es meramente orientativo y, por sí mismo, no autoriza ninguna actividad en ninguna fase"), pero, simultáneamente, adoptó un lenguaje claramente jurídico, aunque fuese en forma de catecismo ("¿Cuándo podré ir a mi segunda residencia dentro de mi misma provincia?; ¿Cuándo se podrá ir al campo o a la playa?; ¿Podemos salir a pasear dos convivientes con el perro?; ¿Puedo hacer una reforma en casa?").

En efecto, a pesar de establecer expresamente la necesidad del "correspondiente instrumento jurídico" para cualquier "cambio, levantamiento o alivio" (p. 3), la realidad es que el lenguaje era claramente normativo al imponer restricciones o establecer autorizaciones:

(...) no se permitirán los desplazamientos entre provincias (...) las visitas a segundas residencias dentro de la provincia en la que se ubica el domicilio habitual estarán permitidas desde la Fase II (...) Desde la Fase 
0, es decir, a partir del 4 de mayo, se permite atender los huertos familiares (...) Una vez se alcance la Fase I se podrá realizar turismo activo (...) Los paseos permitidos a partir del 2 de mayo como parte de las medidas de alivio para la ciudadanía deben realizarse de forma individual o acompañados de un conviviente habitual, en franjas horarias preestablecidas por grupos de edad (...) A partir de la Fase 0 se autoriza la realización de obras de rehabilitación en lugares no cerrados bajo determinadas condiciones de seguridad. También se permiten las reformas en inmuebles siempre y cuando estén vacíos (no habitados) y no se tenga contacto con los vecinos (...) A partir de la Fase 0 puede abrir el comercio minorista que ocupe una superficie menor a 400 metros cuadrados (...) entre cliente y cliente (peluquería) debe mantenerse la distancia de al menos 2 metros (...) será obligatorio llevar mascarilla en el transporte público desde el lunes 4 de mayo (...) Pueden volver a la educación presencial en el centro de manera voluntaria: Los menores de educación infantil y primaria (de 0 a 6 años), si sus progenitores acreditan que deben trabajar fuera de casa. (...) Los alumnos de 6 o más años podrán acudir a los centros para programas de refuerzo educativo. (...) Los actos y espectáculos culturales al aire libre podrán hacerse en la Fase I con menos de 200 personas (...) en la Fase I se podrán celebrar (congresos) respetando la distancia social de más de 2 metros y de menos de 30 asistentes.

En esencia, el plan pretende ser un documento de naturaleza política (hoja de ruta), que a la vez establece delegaciones (en el ministerio de sanidad ${ }^{38}$ ), sin dejar por ello de regular derechos fundamentales (se permitirá/no se permitirá), con

38. El ministro de sanidad recibió el título de "autoridad competente delegada" por el art. 4.2.d del RD 463/2020, de 14 de marzo. un nivel de detalle propio de una norma jurídica (superficie menor a 400 metros; 2 metros; a partir del 4 de mayo; 200/400/800 personas; 30/50/80 asistentes, etc.), y por tanto, válida en el sentido kelseniano. ${ }^{39}$ Hasta se enumeró con todo lujo de detalles quién podía entrar en territorio nacional y quién no (p. 14). De hecho, el Plan fue citado por los tribunales como si de una norma vinculante se tratara. ${ }^{40}$

Si en vez de en un estado de excepción se declaró el estado de alarma, ahora, en vez de aprobar una ley orgánica para regular los derechos fundamentales durante aproximadamente un mes y medio, se

39. "Con el término 'validez' designamos la existencia específica de una norma. Cuando describimos el sentido, o el significado, de un acto que instituye una norma, decimos que, con el acto en cuestión, cierto comportamiento humano es ordenado, mandado, prescrito, preceptuado, prohibido; o bien, admitido, permitido, autorizado. Cuando nosotros, como hemos propuesto anteriormente, recurrimos a la palabra 'deber' con un sentido que comprende todos esos significados, podemos expresar la validez de una norma diciendo que algo debe ser o no; o debe ser hecho o no. (...) La 'existencia' de una norma positiva, su validez, es diferente de la existencia del acto de voluntad cuyo sentido objetivo ella es." (Kelsen, 1982:23).

40. El Plan fue empleado incluso por la jurisprudencia. Así, el Tribunal Superior de Justicia de Barcelona hizo una pormenorizada revisión del plan antes de resolver si procedía o no una manifestación. Nos interesa este párrafo "Del papel integral de indicadores, con los parámetros indicados, resultarán los datos que fundamentarán las decisiones que se adopten en el proceso de desescalada, con un nivel de granularidad territorial suficiente, adecuadas en cada momento a la situación epidemiológica y a la capacidad del sistema sanitario en cada ámbito geográfico relevante". Tribunal Superior de Justicia de Cataluña. Sala de lo Contencioso-Administrativo. Sección $3^{\text {a }}$. Sentencia núm. 1391/2020 de 22 de mayo. 
empleó un panfleto político (iba encabezado por fórmulas como "Este virus, lo paramos unidos"). La misma denominación, Plan para la Transición hacia la Nueva Normalidad, recuerda a la neolengua de George Orwell ("La confusión entre Ciencia y Política, hoy tan apreciada, es el típico método de las modernas formas ideológicas." Kelsen, 1931:376)

Si el Plan aprobado por el Consejo de Ministros se configuró conforme a la apariencia de una norma habilitante, el siguiente paso fue que los derechos fundamentales de los españoles (v. g. libertad de circulación) se regulasen mediante órdenes ministeriales.

En puridad, el Plan de Transición, que no era una norma, estableció qué se podía hacer, y las órdenes del ministro de sanidad, cuándo se podía hacerlo. Es decir, el Real Decreto de alarma delegó en el ministro de sanidad la posibilidad de dictar normas con rango de ley; el Plan de Transición detalló la regulación del derecho a la libre circulación de los ciudadanos; y las órdenes concretaron cuándo. De forma que lo que realmente reguló el derecho fundamental de los españoles a la libre circulación no fue ni siquiera una norma jurídica en sentido estricto, sino un Plan de naturaleza política dotado (al parecer) del carácter de "acto con rango de ley" por haber sido emitido por el Gobierno durante el estado de alarma (el Real Decreto de alarma tampoco dijo nada sobre este Plan, esto es, el Gobierno dictó el plan sin ni siquiera autorizarse a sí mismo a dictar un plan con rango de ley..... ${ }^{41}$

41. Este plan se remitió al Congreso el 29 de abril, en cumplimiento de lo dispuesto en la disposición adicional sexta del Real Decreto 463/2020, de 14 de marzo, disposición que a su vez había sido impuesta por el Congreso en la primera prórroga (sesión del día 25 de marzo,
Las órdenes ministeriales comenzaron regulando el paseo de los menores y se acabó tratando a los adultos como a niños. En efecto, las reglas establecidas para el paseo de los menores (una hora al día, entre las 9 y las 21 horas, y a una distancia no superior a un kilómetro con respecto al domicilio del menor ${ }^{42}$ ), pronto se extendieron a los mayores de 70 años, colectivo que repentinamente se vio desgajado del colectivo de adultos para ser sometidos a unas restricciones aún mayores que las de los niños (solo podían salir a pasear entre las 10 y las 12 horas, y entre las 19 y las 20 horas). ${ }^{43}$ El artículo 8 de la Orden de 3 de mayo estableció que los deportistas profesionales podían realizar "entrenamientos de forma individual y al aire libre, dentro de los límites de la provincia en que resida el deportista"; y el 9, que los deportistas federados (no profesionales) podían realizar entrenamientos al aire libre, dos veces al día (recordemos que los paseos de los deportistas no federados eran de una vez al día), "entre las 6 horas y las 10 horas, y entre las 20 horas y las 23.00 horas, y dentro de los límites de la provincia en la que tengan su

que concedió la prórroga, previa imposición al Gobierno del deber de remitir semanalmente al Congreso información sobre el grado de ejecución de las medidas adoptadas y su eficacia para alcanzar los objetivos propuestos.)

42. Art. 2 de la Orden SND/370/2020, de 25 de abril, sobre las condiciones en las que deben desarrollarse los desplazamientos por parte de la población infantil durante la situación de crisis sanitaria ocasionada por el COVID-19.

43. Artículo 5.1.b de la Orden SND/380/2020, de 30 de abril, sobre las condiciones en las que se puede realizar actividad física no profesional al aire libre durante la situación de crisis sanitaria ocasionada por el COVID-19. 
residencia" 44 Hasta el 30 de mayo no se eliminaron, también mediante orden, las franjas horarias. ${ }^{45}$

Las sucesivas órdenes ministeriales permitían circular por la provincia o isla de referencia, lo que tácitamente excluía la posibilidad de salir fuera de la provincia. ${ }^{46}$ Además, ya sin ambages, el artículo 7 de la Orden de 9 de mayo se titulaba directamente "Libertad de circulación", ${ }^{47}$ porque, en efecto, el derecho constitucional a la libertad de circulación se estaba regulando por la norma reglamentaria de menor rango jerárquico de nuestro ordenamiento jurídico, investida (al parecer) del rango de ley porque un Plan del gobierno de naturaleza no jurídica (al parecer) así lo autorizaba. Había bastado un

44. Orden SND/388/2020, de 3 de mayo, por la que se establecen las condiciones para la apertura al público de determinados comercios y servicios, y la apertura de archivos, así como para la práctica del deporte profesional y federado.

45. La Orden SND/458, de 30 de mayo, para la flexibilización de determinadas restricciones de ámbito nacional establecidas tras la declaración del estado de alarma en aplicación de la fase 3 del Plan para la transición hacia una nueva normalidad, continuó restringiendo la circulación a la provincia, isla o unidad territorial de referencia a efectos del proceso de desescalada, y eliminó las franjas horarias. Se modificó el 6, el 13 y el 18 de junio, finalizando el estado de alarma el día 21 de junio.

46. Artículo 7 de la Orden SND/399/2020, de 9 de mayo, para la flexibilización de determinadas restricciones de ámbito nacional, establecidas tras la declaración del estado de alarma en aplicación de fase 1 del Plan para la transición hacia una nueva normalidad.

47. Orden SND/399/2020, de 9 de mayo, para la flexibilización de determinadas restricciones de ámbito nacional, establecidas para la declaración del estado de alarma en aplicación de la fase 1 del Plan para la transición hacia una nueva normalidad. mes y pico de crisis sanitaria para que la pretenciosa garantía de que los derechos fundamentales se regulasen mediante una ley orgánica, o al menos, mediante un decreto de alarma validado por el Congreso, quedase tácitamente suspendida.

Los intentos de los ciudadanos por impugnar dichas órdenes se toparon con su rango: a pesar de ser una orden ministerial gozaban del rango de una ley, por lo que estaba vetado su cuestionamiento directo. ${ }^{48} \mathrm{Y}$ los tribunales se abstuvieron de conocer amparándose también en ese rango (el Tribunal Supremo recordó que sí tenía competencias para conocer de los decretos legislativos cuando estos exceden del ámbito de la delegación, pero no se atrevió a planteárselo con las órdenes ministeriales ${ }^{49}$ ). Nadie impugnó el Plan del gobierno, probablemente debido a que no era una norma jurídica, aunque en la práctica fuese donde se fijaron las directrices de las órdenes ministeriales.

Según el Tribunal Constitucional el decreto que declara el estado de alarma crea su propio sistema de fuentes (sistema de fuentes del derecho de excepción), de forma que "la decisión gubernamental tiene además un carácter normativo, en cuanto establece el concreto estatuto jurídico del estado que se declara. En otras palabras, dispone la legalidad aplicable durante su vigencia, constituyendo también fuente de habilitación de disposiciones y actos administrativos" (STC 83/16).

48. Tribunal Supremo, Sala de lo ContenciosoAdministrativo, Sección $4^{\text {a }}$, auto de 4 de mayo de 2020.

49. Tribunal Supremo. Sala de lo ContenciosoAdministrativo, sección $4^{\text {a }}$, auto de 6 de mayo de 2020. RJ 2020/1011. En el mismo sentido, el auto de 4 de mayo de 2020 (PROV 2020, 137790) y el auto de 12 de mayo de 2020, (RJ/2020/1006). 
Ahora bien, como hemos observado, la parte realmente problemática de este sistema de fuentes del derecho de excepción no radica en los decretos de alarma y sus prórrogas, que son validados por el Congreso, sino por las "disposiciones y actos administrativos" que quedan "habilitados" por dichos decretos. En efecto, ¿significa que esas "disposiciones y actos administrativos" también gozan del rango de ley, aunque su contenido no esté validado (se dictan en ejecución) por el Congreso?; ¿pueden los ministros dictar disposiciones (órdenes ministeriales) que, unas veces gocen del rango de ley, y otras sean simples reglamentos? Dado que los primeros estarían excluidos de la jurisdicción ordinaria, mientras que los segundos pueden ser directamente declarado nulos por dicha jurisdicción, ¿cómo saber deslindar unos de otros? Lamentablemente, en su sentencia 83/2016 el Tribunal Constitucional no lo aclaró ("Y ello porque las locuciones "valor de ley", "rango de ley" o "fuerza de ley" no quedan exclusivamente circunscritas en nuestro ordenamiento a actos o decisiones de origen parlamentario, pudiendo predicarse también la cualidad de la que son manifestación aquellas locuciones, sin necesidad de entrar ahora en consideraciones más detallada, de actos, decisiones o disposiciones de procedencia gubernamental". (las cursivas son mías).

Como hemos podido comprobar, estos "actos, decisiones o disposiciones de procedencia gubernamental" han tenido una importancia vital durante la pandemia, dado que buena parte de las restricciones de derechos no se regularon en el decreto de alarma, sino precisamente a través de estos actos, de naturaleza jurídica incierta, que no fueron validados por el Congreso pero que los tribunales tampoco quisieron entrar a conocer al declararse incompetentes en razón de la materia.

Pues bien, si el Plan de Desescalada y las órdenes ministeriales eran normas o actos con rango de ley, ¿’por qué no estuvieron sujetos al control del Congreso, que, recordemos, no solo se limita a dar el visto bueno, sino que puede introducir sustanciales modificaciones en su contenido? Hemos de insistir en que, si estos actos y normas gozan del rango de ley, son obligatorios para los tribunales, que además no pueden anularlos.

$\mathrm{Si}$, por el contrario, no gozaban del rango de ley, esto es, consistían en normas de carácter meramente reglamentario (las órdenes, en concreto) o de naturaleza política (el Plan de Desescalada), ¿cómo es que regularon y/o limitaron y/o suspendieron los derechos de los ciudadanos? ¿Cómo es que los tribunales de justicia no se atrevieron a entrar a conocer de su contenido amparándose en que no caían bajo la jurisdicción ordinaria?

La realidad es que durante la pandemia el ordenamiento jurídico se convirtió en un tiovivo. El Real Decreto de alarma no podía suspender derechos, pero al final se suspendían mediante una orden ministerial con rango de ley habilitada a partes iguales por dicho decreto y por el Plan de desescalada del gobierno; los decretos-leyes no pueden restringir derechos fundamentales, pero el que se aprobó regulaba una situación (permisos obligatorios) que, además de restringir el derecho al trabajo, suspendía de facto el derecho a la libre circulación porque reenviaba a los trabajadores al ámbito de aplicación del decreto de alarma; el Plan de desescalada no era ni siquiera una norma jurídica, pero al mismo tiempo se erigía en un acto del Gobierno con rango de ley porque detalla- 
ba al milímetro cómo ejercer la libertad de circulación de los españoles; el decreto de alarma no restringió siquiera el derecho a la libre manifestación y/o reunión, pero limitó el derecho que los hacía posible (la libre circulación); y, por último, las limitaciones más fuertes durante la pandemia no se generaron mediante el sistema de fuentes del derecho de excepción (alarma), sino con el sistema de fuentes del derecho ordinario, lo que permitió suspender el derecho de manifestación y/o de reunión, así como el derecho al trabajo, pero convirtió a los tribunales en "defensores de la Constitución". 50

Con razón los delegados del gobierno quisieron prohibir derechos no limitados ni siquiera por el estado de alarma; algunas administraciones públicas crearon declaraciones juradas de desplazamiento antes de que ninguna norma jurídica las exigiera; algunas comunidades autónomas propusieron crear pasaportes inmunitarios con derechos sociales incorporados; la policía comenzó a pedir los tickets de compra de comida como si en alguna norma figurase la distancia a la que debía estar un hipotético supermercado; y algunos ayuntamientos hasta se han atrevido a intentar confinar a sus conciudadanos en esta fase de "nueva normalidad" que vivimos, saltándose cualquier escrúpulo competencial. Por eso los tribunales du-

50. "Los tribunales con facultades decisorias en procesos jurisdiccionales de los órdenes civil, penal y contencioso administrativo no son, en sentido estricto, defensores de la Constitución. El error de señalarlos como tales es muy comprensible porque ejercen el denominado derecho material de control judicial que consiste en comprobar si las leyes ordinarias están de acuerdo, en su contenido, con los preceptos constitucionales, llegando en caso de colisión a negar vigencia a las leyes que no cumplan ese requisito." Schmitt (1929:27). daban sobre en qué situación estábamos, qué era impugnable y qué no ante la jurisdicción ordinaria, y en qué medidas unos derechos están conectados a otros hasta el punto de que la limitación de uno supone la suspensión de facto de otros. Estábamos comenzando a deslizarnos por la pendiente del decisionismo (Schmitt, 1934:269). Probablemente la gravedad de la situación explicaría la pasividad a la hora de cuestionar el entrecruzamiento entre los estados y los sistemas de fuentes.

Tomamos prestada la cita de Offner a Kelsen, que podría aplicarse perfectamente a la forma en que se vistió el santo en nuestro ordenamiento jurídico: "Nosotros ni sabemos ni nos preocupa qué leyes debéis dictar, ya que ello pertenece al arte, al que somos ajenos, de la legislación. Dictad las leyes que queráis. Cuando lo hayáis hecho, os explicaremos en latín qué leyes habéis promulgado"" (Offner, en Pasukanis, 1976)

\subsection{Por criterios no jurídicos}

Distinguidos constitucionalistas, como Cruz Villalón (2020b) o Pérez Royo (en Guindal, 2020), han apoyado la decisión del Gobierno de decretar el estado de alarma y no el de excepción. Para ello, se han basado en el criterio de "razonabilidad", esto es, que, atendidas las circunstancias de este caso concreto, era plausible decretar la alarma.

Esto nos reenvía a variables no jurídicas que deben tenerse en cuenta, de forma que el criterio de demarcación entre la alarma y la excepción, o entre estas y las medidas extraordinarias del sistema ordinario de fuentes, no residiría en causas y/o efectos, sino en criterios de mera 
oportunidad en función de circunstancias fácticas ad hoc.

A raíz de la pandemia, Cotino (2020) ha recopilado en un excelente estudio las medidas previstas en el sistema de fuentes ordinario, incluso con amparo constitucional, para una situación como la que vivimos. ${ }^{51}$ Pues bien, ha hallado un conglomerado de no menos de cien normas, entre estatales y autonómicas, que posibilitan adoptar prácticamente cualquier medida ante casi cualquier evento. Aunque el objeto de nuestro estudio se centra a los meses de marzo y junio, en estos momentos, octubre, estamos contemplando cómo diversas poblaciones están siendo confinadas por la pandemia con la legislación ordinaria y amparo judicial. Salvo Madrid.

En efecto, una norma dictada al amparo de las fuentes ordinarias estableció una serie de medidas para combatir el coronavirus en la comunidad madrileña. ${ }^{52}$ Sin embargo, el Tribunal de Justicia de Madrid la revocó argumentando que violentaba derechos fundamentales. ${ }^{53}$ Como reacción, el Gobierno de la nación ha de-

51. Por otra parte, Nogueira destaca cómo el primer confinamiento que se generó como consecuencia de la pandemia, en Haro, no tuvo "ningún ropaje jurídico, o por lo menos no dotado de publicidad" (Nogueira, 2020).

52. Resolución de 30 de septiembre de 2020, de la Secretaría de Estado de Sanidad, por la que se da publicidad al Acuerdo del Consejo Interterritorial del Sistema Nacional de Salud sobre la Declaración de Actuaciones Coordinadas en Salud Pública para responder ante situaciones de especial riesgo por transmisión no controlada de infecciones causadas por el SARS-Cov-2, de fecha 30 de septiembre de 2020. (BOE. 1 de octubre de 2020).

53. Tribunal Superior de Justicia de Madrid. Sala de lo Contencioso-Administrativo. Sección octava. Proc. Ordinario 1224/2020 P-01. cretado el estado de alarma en Madrid estableciendo las mismas medidas. ${ }^{54}$ A su vez, la fiscalía ha recurrido el auto del TSJ de Madrid. Pues bien, si el Tribunal Supremo estima su recurso, nos podemos encontrar con dos normas, una procedente del sistema de fuentes ordinario y otro del derecho de excepción, que establezcan simultánea y válidamente lo mismo, esto es, idénticas medidas por idénticas causas. De hecho, ambas podrían acabar en el Tribunal Constitucional por los mismos motivos (v. gr., un recurso de amparo).

Al mismo tiempo, el TSJ de Castilla y León ha validado similares medidas en otras localidades castellanas, sin que haya sido necesario decretar el estado de alarma. Tanto la comunidad madrileña como la castellana están regidas por dirigentes del Partido Popular. ¿A qué se debe esa diferencia de trato jurídico?

La única diferencia relevante es que, en el caso de Castilla y León la administración autonómica estaba de acuerdo con las medidas, mientras que en Madrid no. El gobierno nacional decretó el estado de alarma debido a una confrontación de naturaleza política con el gobierno autonómico madrileño.

Esto es, la causa de este segundo decreto de alarma no reside en la pandemia (ya se estaba adoptando medidas con el sistema ordinario de fuentes), sino por el rechazo de la comunidad madrileña, apoyado por la jurisdicción ordinaria, a adoptar las medidas propuestas por la administración central. El criterio de distinción entre el

54. Real Decreto 900/2020, de 9 de octubre, por el que se declara el estado de alarma para responder ante situaciones de especial riesgo por transmisión no controlada de infecciones causadas por el SARS-CoV-2. 
sistema de fuentes del derecho de excepción y el sistema de fuentes ordinario no ha residido, en este caso, en criterios estrictamente jurídicos (aplicación ipso facto de la Ley 4/81 por las causas allí establecidas), sino por variables no jurídicas (oportunidad, razonabilidad, rédito electoral de una confrontación con el gobierno central, mostrar quién manda realmente, etc.). A raíz del auto del TSJ de Madrid, otro ilustre jurista, Tomás de la QuadraSalcedo, sostenía que: "podemos preguntarnos si corresponde a los jueces decidir algo que no está en las normas, sino en decisiones políticas difícilmente asequibles al derecho". Esto es, si el poder político decide que lo mejor es un confinamiento masivo o parcial con arreglo al sistema de fuentes ordinario, el poder judicial no debería poder intervenir. Criterio político, en suma.

Esto nos reenvía también a las causas fácticas del primer decreto de alarma. Si el Gobierno de la Nación hubiese empleado el sistema de fuentes ordinario para la adopción de medidas extraordinarias en febrero, cuando se vio venir la pandemia tras innumerables advertencias y con el premonitorio espectáculo que ofrecía la situación en Italia, entonces probablemente no habría hecho falta un confinamiento domiciliario masivo en marzo. De hecho, la situación en estos momentos es la misma (si se mueren menos personas es porque los más mayores están más protegidos) y el estado de alarma no está haciendo falta. Basta con el sistema ordinario de fuentes.

Esto es, el decreto de estado de alarma era "razonable" el 14 de marzo porque en las semanas previas no se adoptó ninguna medida basada en el sistema ordinario de fuentes. Si no, era injustificable. Y los hechos ahora no desmienten esta afirma- ción. Lo que nos reenvía a variables políticas, de oportunidad, eficacia, flexibilidad, etc., con un componente de batalla electoralista de fondo que no puede ser obviado a la hora de explicar por qué se opta por un sistema y no por otro. La anormal "normalidad jurídica" de la segunda semana de marzo explicaría el salto al estado de alarma del día 14; no, por tanto, la Ley 4/81 ni el artículo 116 de la Constitución. ${ }^{55}$

\section{Conclusiones}

Aparte de algunas obviedades, como la necesidad de actualizar nuestro ordenamiento jurídico a los requerimientos de la época actual, ${ }^{56}$ coordinar las legislaciones estatal y autonómica, etc., estimo que de lo expuesto podemos extraer dos conclusiones relevantes:

$\mathbf{1}^{\mathbf{0}}$ ) Los criterios de distinción entre los sistemas de fuentes del derecho de excepción y el ordinario, así como entre los estados de alarma y de excepción, resi-

55. Fuertes destaca la celeridad de los acontecimientos desde el punto de vista jurídico en la semana del 7 al 14 de marzo. Se comenzó como "si nada estuviera pasando" y en menos de una semana ya se había decretado el estado de alarma.

56. Si algo ha puesto de manifiesto la pandemia desde el punto de vista jurídico, es la necesidad de actualizar la normativa para situaciones excepcionales. Alonso (2020) relata cómo, en las sesiones de control del gobierno, se permitió a los parlamentarios emplear medios telemáticos para votar, pero no para defender las propuestas. Ambas acciones estaban prohibidas por el Reglamento del Congreso porque no se había previsto una situación de pandemia. La forma en que se resolvió, permitir una pero no la otra, es obviamente injustificable, ya que la portavoz de uno de los partidos estaba embarazada, y lógicamente corría peligro si acudía personalmente a defender su propuesta. 
den en variables no jurídicas; y cuando se sujetan al Derecho, el resultado es el caos normativo que vivimos en estos momentos. Unos juristas, incluido tribunales, aceptan las medidas de confinamiento basadas en el sistema ordinario de fuentes; otros, incluido tribunales, que debe declararse el estado de alarma; y otros, minoritarios, pero no irrelevantes, incluido tribunales, que debe declararse el estado de excepción.

La solución última que dicte el Tribunal Constitucional se aceptará como corresponde a un Estado de Derecho, pero en el fondo es un problema irresoluble desde un punto de vista estrictamente lógico. Simplemente, nuestro ordenamiento jurídico no estaba preparado para algo como una pandemia de alcance global y duradera en el tiempo, y se opte por una u otra solución, acaba en aporía.

Para decretar el estado de excepción y suspender derechos se requiere una tramitación parlamentaria inviable si el evento es sorpresivo e impredecible; pero el estado de alarma no permite adoptar las medidas necesarias para afrontar con éxito los efectos de un evento sorpresivo e impredecible, en especial, suspender la libre circulación, las manifestaciones y las reuniones. Como resultado de estas contradicciones, el 14 de marzo se decretó el estado de alarma y, donde las restricciones no alcanzaban, se completó con el sistema de fuentes ordinario para poder suspender derechos constitucionales, introduciéndonos en un estado de excepción de facto con la loable intención de evitar una catástrofe humanitaria, pero con las lógicas, insalvables y turbadoras consecuencias jurídicas que estamos observando.

Por lo pronto, las sanciones impuestas en este periodo, tanto administrativas como penales, podrían ser nulas de pleno derecho, lo que restaría coherencia al sistema. Pero con todo, lo peor es que se daña la credibilidad del Estado de Derecho, refractario a la improvisación, los parches y los atajos.

$\mathbf{2}^{\mathbf{0}}$ ) La pandemia ha abierto una brecha peligrosa en nuestro ordenamiento jurídico. En efecto, si la normativa dictada durante el estado de alarma es válida jurídicamente, entonces sería viable que un gobierno, incluso el producto de una escueta mayoría simple, confinara a la población en sus domicilios sin control de la jurisdicción ordinaria (sería una norma con fuerza de ley), sin control parlamentario (que tardaría quince días en emitir la validación, acto que, no lo olvidemos, no puede revocar lo ya hecho), y con una hipotética intervención del Tribunal Constitucional que podría ser temerariamente tardía.

En quince días se pueden hacer muchas cosas, entre ellas, desmantelar un Estado de Derecho. Advertía Isaiah Berlín (2019) de la celeridad con que Hitler o Lenin se alzaron con el poder en sus respectivos países. Aunque estoy planteando un mero ejercicio mental, la realidad es que, si aceptamos que durante un estado de alarma se puede restringir casi absolutamente la movilidad de la población, acabamos de abrir un agujero de consecuencias imprevisibles para quien actúe con mala fe. Sería toda una paradoja que el estado de alarma, hasta hace poco denostado e incluso casi abrogado por desuso, ${ }^{57}$ pudiese ser empleado como

57. Véase Cano, en Aba, 2011. Resulta también significativa, en este sentido, la reflexión formulada en 2011 por el Defensor del Pueblo Navarro. "Las calamidades más graves y las crisis sanitarias (vacas locas, fiebre aftosa, inundaciones, etc) se habían resuelto hasta ese momento sin 
arma contra el propio sistema democrático. Si no se rectifica pronto y se adecúan las normas a situaciones como la vivida, quizá algún día paguemos un alto coste por nuestra ingenuidad.

\section{Bibliografía}

ABA CATOIRA, Ana (2011): "El Estado de Alarma en España". Teoría y Realidad Constitucional, núm. 28. pp. 305-334.

ÁlVAREZ GARCÍA, Francisco Javier (2020): "Estado de alarma o de excepción". Estudios penales y criminológicos. Vol. XL. pp. 1-20.

ALONSO PRADA, Víctor (2020): "EI control del Congreso de los Diputados al Gobierno y la actividad parlamentaria durante el Estado de alarma". Gabilex. Revista del Gabinete Jurídico de CastiIla-La Mancha. № 21. pp. 73-108.

BERLín, Isaiah (2019): El sentido de la realidad. Sobre las ideas y su historia. Título original: The Sense of Reality. Studies in ideas and their History. Edición de Henry Hardy. Introducción por Patrick Gardiner. Traducción de Pedro Cifuentes. Taurus.

BUENO, Gustavo (1996): El mito de la cultura. Pentalfa ediciones. 1996.

COTINO HUESO, Lorenzo (2020): "Los derechos fundamentales en tiempos del coronavirus. Régimen general y garantías y especial atención a las restricciones de excepcionalidad ordinaria". El Cronista del Estado Social y Democrático de Derecho. Núm. 86/87. Marzo/Abril. pp. 88101.

decretarse el estado de alarma, hasta el punto de hablarse de una 'mutación constitucional' por la que el estado de alarma llegaba a ser, debido a su desuso, innecesario, bastando con la legislación ordinaria”. (Enériz, 2011).
CRUZ VILLALÓN, Pedro:

(2020a): "La Constitución bajo el estado de alarma". El País. 17 de abril. (2020b): Una precisión todavía. El País. 19 de abril de 2020.

ENÉRIZ OLAECHEA, Francisco Javier. (2011): "La declaración del estado de alarma para la normalización del transporte aéreo". Revista Aranzadi Doctrinal núm. 9/2011. BIB 2010/2868. pp. 79-94.

DE LA QUADRA SALCEDO FERNÁNDEZ DEL CASTILLO, Tomás (2020) "Abracadabra" EL País, 10 de octubre.

FUERTES LÓPEZ, F. (2020): "Cronología del coronavirus: hechos y regulación". Aranzadi SAU. BIB 2020/12221. pp. 5-6 GARCÍA DE ENTERRÍA RAMOS, Andrea (2020): "La actuación de las Cortes Generales durante el estado de alarma para la gestión de la crisis del covid-19". Revista de las Cortes Generales. Número 108. Primer semestre. pp. 245-288.

GUINDAL, Carlota (2020): "Estado de alarma: ¿imprescindible o excesivo?". La Vanguardia. 24/05/2020.

GONZÁLEZ LÓPEZ, Juan José (2020): "Reales Decretos de declaración y prórroga del estado de alarma: naturaleza jurídica, control jurisdiccional y responsabilidad patrimonial". Gabilex. Revista del Gabinete Jurídico de Castilla-La Mancha. $\mathrm{N}^{\circ} 21$. pp. 109-132.

KELSEN, Hans (1931): ¿Quién debe ser el defensor de la Constitución? En (2019): Carl Schmitt y Hans Kelsen La polémica Schmitt/Kelsen sobre la justicia constitucional: El defensor de la Constitución versus ¿quién debe ser el defensor de la Constitución? Estudio de contextualización de Germán Gómez Orfanel. Estudio preliminar de Giorgio Lombardi. Traducción de Manuel Sánchez Sarto y Roberto J Brie. Revisión de la traducción, anotaciones y bibliografía a cargo de Alberto Oehling de los Reyes. Tecnos. 
KELSEN, Hans (1982): Teoría pura del derecho. Título original "Reine Rechtslehre". (1960). Traducción de la segunda edición en alemán, por Roberto J. Vernengo. Universidad Nacional Autónoma de México.

NOGUEIRA LÓPEZ, Alba (2020): "Confinar el coronavirus. Entre el viejo derecho sectorial y el derecho de excepción." El Cronista del Estado Social y Democrático de Derecho. Núm. 86/87. Marzo/Abril. OFFNER, J (1923): Das soziale Rechtsdenken (El pensamiento social jurídico).

PASUKANIS, Eugeni (1976): Teoría General del Derecho y Marxismo. Título de la edición original; Obschaia Teoria Prava i Marxisma. Presentación y traducción de Virgilio Zapatero. Editorial Labor SA.

PÉREZ ROYO, Javier (2020): ¿Por qué el estado de alarma sigue siendo imprescindible? elDiario.es. 15/05.

SCHMITT, Carl:

(1934): Sobre los tres modos de pensar de la ciencia jurídica. En SCHMITT, Carl (1934): Posiciones ante al derecho. (2012). Estudio preliminar, traducción y notas Monserrat Herrero. Tecnos.

(1929): El Defensor de la Constitución. En (2019): Carl Schmitt y Hans Kelsen La polémica Schmitt/Kelsen sobre la justicia constitucional: El defensor de la Constitución versus ¿quién debe ser el defensor de la Constitución? Estudio de contextualización de Germán Gómez Orfanel. Estudio preliminar de Giorgio Lombardi. Traducción de Manuel Sánchez Sarto y Roberto J Brie. Revisión de la traducción, anotaciones y bibliografía a cargo de Alberto Oehling de los Reyes. Tecnos. 